\title{
Dietary Epidemiology of Essential Tremor: Meat Consumption and Meat Cooking Practices
}

\author{
Elan D. Louis ${ }^{\mathrm{a}-\mathrm{d}}$ Garrett A. Keating $^{\mathrm{e}}$ Kenneth T. Bogen ${ }^{\mathrm{e}}$ Eileen Rios $^{\mathrm{a}}$ \\ Kathryn M. Pellegrino ${ }^{a}$ Pam Factor-Litvak ${ }^{d}$ \\ ${ }^{a}$ G.H. Sergievsky Center, ${ }^{b}$ Department of Neurology, and ${ }^{\mathrm{C} T a u b}$ Institute for Research on Alzheimer's Disease and \\ the Aging Brain, College of Physicians and Surgeons, Columbia University, and d Department of Epidemiology, \\ Mailman School of Public Health, Columbia University, New York, N.Y., e Energy and Environmental Directorate, \\ Lawrence Livermore National Security, LLC, Livermore, Calif., USA
}

\section{Key Words}

Dietary epidemiology, essential tremor • Essential tremor •

Toxin $\cdot$ Harmane $\cdot$ Diet, tremor $\cdot$ Metabolism, meat

\begin{abstract}
Background/Aim: Harmane [1-methyl-9H-pyrido(3,4-b)indole] is a tremor-producing neurotoxin. Blood harmane concentrations are elevated in essential tremor (ET) patients for unclear reasons. Potential mechanisms include increased dietary harmane intake (especially through well-cooked meat) or genetic-metabolic factors. We tested the hypothesis that meat consumption and level of meat doneness are higher in ET cases than in controls. Methods: Detailed data were collected using the Lawrence Livermore National Laboratory Meat Questionnaire. Results: Total current meat consumption was greater in men with than without ET (135.3 \pm 71.1 vs. $110.6 \pm 80.4 \mathrm{~g} /$ day, $\mathrm{p}=0.03$ ) but not in women with versus without ET $(80.6 \pm 50.0$ vs. $79.3 \pm 51.0 \mathrm{~g} / \mathrm{day}, \mathrm{p}=0.76)$ In an adjusted logistic regression analysis in males, higher total current meat consumption was associated with ET $(O R=1.006, p=0.04$, i.e., with 10 additional $\mathrm{g} /$ day of meat, odds of ET increased by 6\%). Male cases had higher odds of being in the highest than lowest quartile of total current
\end{abstract}

\section{KARGER}

Fax +41613061234 E-Mail karger@karger.ch www.karger.com
(ㄷ) 2008 S. Karger AG, Basel

Accessible online at: www.karger.com/ned meat consumption (adjusted $O R=21.36, p=0.001$ ). Meat doneness level was similar in cases and controls. Conclusion: This study provides evidence of a dietary difference between male ET cases and male controls. The etiological ramifications of these results warrant additional investigation.

Copyright $\odot 2008$ S. Karger AG, Basel

\section{Introduction}

Essential tremor (ET) is one of the most common neurological diseases [1-3]. Genetic factors clearly play a role in disease etiology $[4,5]$. Environmental factors likely also play a role [5]. The study of potentially modifiable environmental factors is important; their identification forms the basis for interventional studies aimed at risk reduction.

Harmane [1-methyl-9H-pyrido(3,4-b)indole] is a potent neurotoxin [6] present in the human diet in a number of foods [7]. As a heterocyclic amine [6], it is comprised of several five- and six-ringed structures, which contain an amine group. There is a structural similarity to the neurotoxin MPTP (1-methyl 4-phenyl 1,2,3,6-tetrahydropyridine), which has a two-ring structure. Harmane

Dr. Elan Louis

Unit 198, Neurological Institute

710 West 168th Street

New York, NY 10032 (USA)

Tel. +1 212305 9194, Fax +1 212305 1304, E-Mail edl2@columbia.edu 
crosses the blood-brain barrier through an active uptake mechanism, and brain concentrations are higher than those in the blood [7]. Laboratory animals exposed to harmane and other heterocyclic amines develop tremor $[8,9]$ accompanied by destruction of inferior olivary and cerebellar tissue [10]. Blood harmane concentration was found to be elevated in ET cases $[11,12]$.

Harmane is particularly abundant in meats, and furthermore, certain cooking practices (e.g., long cooking times) increase its concentration. The mechanisms for the observed higher blood harmane concentrations in ET are not clear but could include increased dietary intake and/or genetic-metabolic factors [12]. Our goal was to further examine the emerging link between this neurotoxin and ET. In the current study, our hypothesis was that meat consumption and level of meat doneness would be higher in ET cases than controls.

\section{Methods}

\section{ET Cases and Controls}

ET cases were cared for by neurologists at the Neurological Institute of New York, Columbia University Medical Center (CUMC) $[12,13]$. They were identified from a computerized database of patients billed in the last 3 years, supplemented by a computerized database at the Center for Parkinson's Disease and Other Movement Disorders, CUMC, which listed patients seen in the last 10 years. All patients had received a diagnosis of ET from their treating neurologist at the Neurological Institute. All ET cases in these databases were identified for enrollment in a study of the environmental epidemiology of ET, which began in 2005. Office records were reviewed, and cases with physical signs or diagnoses of dystonia, Parkinsonism (rigidity or bradykinesia) or spinocerebellar ataxia were excluded.

Controls were identified from the New York metropolitan area using random digit telephone dialing. These controls were frequency matched to CUMC cases based on 5-year age strata, gender and ethnicity (non-Hispanic white, non-Hispanic AfricanAmerican, Hispanic). The controls were ascertained from the same source population as the cases in the New York Tri-State Region, i.e., the controls were selected from the same set of ZIP codes in New York, New Jersey and Connecticut as were the cases. The majority of these controls also received their health care at the same medical center as did the ET cases (i.e., CUMC) $[12,13]$.

\section{Study Evaluation}

Participants were evaluated in person by a trained tester. The tester collected demographic and clinical data.

In addition, detailed data on current (i.e., during the past year) meat consumption were collected using the Lawrence Livermore National Laboratory Meat Questionnaire [14, 15]. The questionnaire, which takes approximately $20 \mathrm{~min}$ to complete, includes questions related to consumption of 15 specific meats (e.g., hamburgers; pork chops; grilled, barbecued or broiled chicken; meat or sausage patties), including: (1) frequency of consumption (coded into nine categories ranging from never to every day) and (2) portion size (number of standard sized portions as represented in photographs presented to participants), which was converted into grams. A summary measure, total current meat consumption (i.e., consumption in g/day of all 15 meat types combined), was calculated for each participant.

In addition to the assessment of meat consumption, using the Lawrence Livermore National Laboratory Meat Questionnaire $[14,15]$, the tester also assessed meat doneness. A series of photographs of the level of meat doneness was used for six meat types to aid the participant in identifying four doneness levels $(1=$ rare, $4=$ charred). In a test-retest reliability study of 22 participants ( 2 months later), responses were reproducible, with most intraclass correlation values being between 0.60 and 0.90 (e.g., intraclass correlation coefficients for chicken doneness $=0.70$ and for hamburger doneness $=0.60)$. Also, in a sample of 138 participants ( 81 ET cases and 57 controls), total meat consumption (g/day), which was estimated using this questionnaire, was correlated with total animal protein consumption in grams estimated using a semiquantitative food frequency questionnaire [16] (Spearman rho = $0.25, p=0.003$ ). A summary measure, total current meat doneness (i.e., the doneness levels for all 6 meat types combined), was calculated for each participant.

Weight and height were assessed using a balance scale (model 5600; Scale-Tronix, White Plains, N.Y., USA) and a movable anthropometer (GPM, Martin type; Pfister Inc., Carlstadt, N.J., USA). Body mass index was weight in kilograms divided by the square of height in meters. The tester also videotaped a tremor examination in all participants [17], and each of 12 videotaped action tremor items was rated by E.D.L. on a scale from 0 to 3, resulting in a total tremor score [range $=0-36$ (maximum)]. The diagnosis of ET was confirmed by E.D.L. using published diagnostic criteria (moderate or greater amplitude tremor during three activities or a head tremor) [17]. None of the cases or controls had Parkinson's disease or dystonia.

\section{Additional Dietary Data}

Additional dietary data were available on a subset of 81 ET cases ( 31 male) and 57 controls (26 male). These data had been collected in person by a trained tester using a semiquantitative food-frequency questionnaire [16]. This 20-min questionnaire included questions on frequency of consumption of 61 foods and questions on the use of vitamins and mineral supplements within the past year. These food frequency data were used to compute daily carbohydrate intake (g) and fat intake (g).

\section{Statistical Analyses}

Chi-square and Student's t tests were used to compare demographic characteristics of cases and controls (table 1). Given the large number of meat types assessed $(n=15)$ and the issue of multiple comparisons, a summary measure, total current meat consumption (i.e., consumption of all 15 meat types combined, expressed as grams of meat per day), was calculated for each participant, with this summary measure being used for our main case-control comparison. Because this summary measure was not normally distributed, a Mann-Whitney test was used for casecontrol comparisons. Given the large number of meats for which doneness levels were assessed $(n=6)$ and the issue of multiple comparisons, a summary measure, total current meat doneness 
Table 1. Demographic characteristics of ET cases and controls

\begin{tabular}{|c|c|c|c|c|}
\hline & \multicolumn{2}{|l|}{ Men } & \multicolumn{2}{|l|}{ Women } \\
\hline & $\begin{array}{l}\text { ET cases } \\
(\mathrm{n}=56)\end{array}$ & $\begin{array}{l}\text { controls } \\
(\mathrm{n}=60)\end{array}$ & $\begin{array}{l}\text { ET cases } \\
(\mathrm{n}=69)\end{array}$ & $\begin{array}{l}\text { controls } \\
(\mathrm{n}=65)\end{array}$ \\
\hline Age, years & $66.5 \pm 15.7$ & $65.0 \pm 15.4$ & $65.0 \pm 15.2$ & $67.1 \pm 11.9$ \\
\hline \multicolumn{5}{|l|}{ Race } \\
\hline Non-Hispanic white & $52(92.9 \%)$ & $53(88.2 \%)$ & $63(92.6 \%)$ & $53(82.8 \%)$ \\
\hline Non-Hispanic black & $1(1.8 \%)$ & $4(6.7 \%)$ & $3(4.4 \%)$ & $5(7.8 \%)$ \\
\hline Hispanic & $2(3.6 \%)$ & $3(5.0 \%)$ & $1(1.5 \%)$ & $4(6.3 \%)$ \\
\hline Other & $1(1.8 \%)$ & $0(0.0 \%)$ & $1(1.5 \%)$ & $2(3.1 \%)$ \\
\hline Years of education & $15.3 \pm 4.1$ & $15.7 \pm 3.5$ & $14.6 \pm 3.5$ & $15.1 \pm 3.4$ \\
\hline Current cigarette smokers & $4(8.0 \%)$ & $5(8.6 \%)$ & $6(10.7 \%)$ & $3(4.6 \%)$ \\
\hline \multicolumn{5}{|l|}{ Marital status } \\
\hline Married & $33(60.0 \%)$ & $27(45.0 \%)$ & $26(38.2 \%)$ & $19(29.2 \%)$ \\
\hline Widowed & $4(7.3 \%)$ & $6(10.0 \%)$ & $18(26.5 \%)$ & $21(32.3 \%)$ \\
\hline Never married & $8(14.5 \%)$ & $12(20.0 \%)$ & $12(17.6 \%)$ & $15(23.1 \%)$ \\
\hline Divorced & $7(12.7 \%)$ & $10(16.7 \%)$ & $11(16.2 \%)$ & $6(9.2 \%)$ \\
\hline Separated & $1(1.8 \%)$ & $1(1.7 \%)$ & $0(0.0 \%)$ & $1(1.5 \%)$ \\
\hline Remarried & $2(3.6 \%)$ & $4(6.7 \%)$ & $1(1.5 \%)$ & $3(4.6 \%)$ \\
\hline \multicolumn{5}{|l|}{ Current living } \\
\hline Home & $56(100 \%)$ & $60(100 \%)$ & $66(95.7 \%)$ & $65(100 \%)$ \\
\hline Other (assisted living) & $0(0 \%)$ & $0(0 \%)$ & $3(4.3 \%)$ & $0(0 \%)$ \\
\hline Lives alone & $14(25.5 \%)$ & $21(35.0 \%)$ & $33(48.5 \%)$ & $35(53.8 \%)$ \\
\hline Years since last hospitalization & $14.7 \pm 24.4$ & $19.1 \pm 25.8$ & $13.3 \pm 16.8$ & $14.5 \pm 17.2$ \\
\hline Body mass index & $27.5 \pm 4.0$ & $27.1 \pm 3.7$ & $26.9 \pm 7.0$ & $27.8 \pm 5.6$ \\
\hline
\end{tabular}

(i.e., the doneness levels for all 6 meat types combined), was calculated for each participant, with this summary measure being used for our main case-control comparison (Mann-Whitney test). Dietary behavior generally differs by gender; therefore, each comparison was stratified by gender (i.e., male cases vs. male controls, female cases vs. female controls).

In logistic regression analyses (outcome $=\mathrm{ET}$ vs. control), the independent variable was total current meat consumption in some analyses and total current meat doneness level in other analyses. The choice of covariates in adjusted analyses was based on current case-control differences and results of published analyses $[11,12]$. For some analyses, ET cases and controls were stratified into quartiles of total current meat consumption $(<50.8 \mathrm{~g} / \mathrm{day}$, $50.8-88.5 \mathrm{~g} /$ day, $88.6-132.8 \mathrm{~g} /$ day, $>132.8 \mathrm{~g} /$ day). In a logistic regression analysis, the outcome variable was ET versus control and the independent variable was quartile of total current meat consumption. The choice of covariates in adjusted analyses was based on current case-control differences and results of published analyses $[11,12]$. To compare total current meat consumption by total tremor score, Spearman's rho was used.

With our sample size, we had $88.3 \%$ power to detect a $50 \%$ increase in total current meat consumption between ET cases and controls in gender-stratified analyses. We had $84.9 \%$ power to detect a $20 \%$ increase in total current meat doneness level between ET cases and controls in gender-stratified analyses. These calculations assumed alpha $=0.05$

Dietary Epidemiology of Essential Tremor

\section{Results}

There were 125 ET cases (mean disease duration 19.2 \pm 16.3 years) and 125 controls. Cases and controls, coming from the same source population, were similar in terms of each of the demographic characteristics examined (table 1 , all $\mathrm{p}$ values $>0.10$ ).

Among males, total current meat consumption was greater in cases than controls (mean \pm SD): $135.3 \pm 71.1$ $\mathrm{g} /$ day versus $110.6 \pm 80.4 \mathrm{~g}$ /day (median values $111.5 \mathrm{vs}$. $104.4 \mathrm{~g}$ /day; Mann Whitney $\mathrm{z}=2.16, \mathrm{p}=0.03$; fig. 1). Total current meat consumption was similar in female cases and female controls: $80.6 \pm 50.0 \mathrm{~g} /$ day versus $79.3 \pm$ $51.0 \mathrm{~g} /$ day (median values 72.8 vs. 69.7 g/day; MannWhitney $\mathrm{z}=0.31, \mathrm{p}=0.76$; fig. 1 ). In a logistic regression analysis in males adjusting for age (years), education (years), body mass index and current smoking (yes vs. no), higher total current meat consumption was associated with $\mathrm{ET}(\mathrm{OR}=1.006,95 \% \mathrm{CI}=1.000-1.011, \mathrm{p}=0.04$; i.e., with each 10 additional $\mathrm{g} /$ day of meat, the odds of ET was increased by $6 \%$ and with 20 additional g/day by $12 \%$, etc.). Also adjusting for marital status, lives alone and years since last hospitalization (as well as age, education,

Neuroepidemiology 2008;30:161-166 
Table 2. Quartiles of total current meat consumption

\begin{tabular}{llllll}
\hline Quartile of meat consumption & \multicolumn{3}{l}{ Men } & & \multicolumn{2}{l}{ Women } \\
\cline { 2 - 3 } \cline { 5 - 6 } & $\begin{array}{l}\text { ET cases } \\
(\mathrm{n}=56)\end{array}$ & $\begin{array}{l}\text { controls } \\
(\mathrm{n}=60)\end{array}$ & & $\begin{array}{l}\text { ET cases } \\
(\mathrm{n}=69)\end{array}$ & $\begin{array}{l}\text { controls } \\
(\mathrm{n}=65)\end{array}$ \\
\hline Lowest quartile & $3(5.4 \%)$ & $15(25.0 \%)$ & & $21(30.4 \%)$ & $23(35.4 \%)$ \\
Quartile 2 & $10(17.9 \%)$ & $13(21.7 \%)$ & & $21(30.4 \%)$ & $19(29.2 \%)$ \\
Quartile 3 & $17(30.4 \%)$ & $18(30.0 \%)$ & & $15(21.7 \%)$ & $13(20.0 \%)$ \\
Highest quartile & $26(46.4 \%)$ & $14(23.3 \%)$ & & $12(17.4 \%)$ & $10(15.4 \%)$ \\
\hline
\end{tabular}

${ }^{*} \mathrm{p}<0.01$.

Table 3. Quartiles of total current meat consumption in men: logistic regression analyses (OR; 95\% CI in parentheses)

\begin{tabular}{lll}
\hline $\begin{array}{l}\text { Quartile of meat } \\
\text { consumption }\end{array}$ & Unadjusted & Adjusted $^{\mathrm{a}}$ \\
\hline Lowest quartile & 1 (reference) & 1 (reference) \\
Quartile 2 & $3.85(0.87-17.04)$ & $11.41(1.71-76.01)$ \\
& $\mathrm{p}=0.08$ & $\mathrm{p}=0.01$ \\
Quartile 3 & $4.72(1.16-19.26)$ & $9.67(1.69-55.35)$ \\
& $\mathrm{p}=0.03$ & $\mathrm{p}=0.01$ \\
Highest quartile & $9.29(2.29-37.64)$ & $21.36(3.52-129.51)$ \\
& $\mathrm{p}=0.002$ & $\mathrm{p}=0.001$ \\
\hline
\end{tabular}

a Adjusted for age, education, body mass index, and smoking

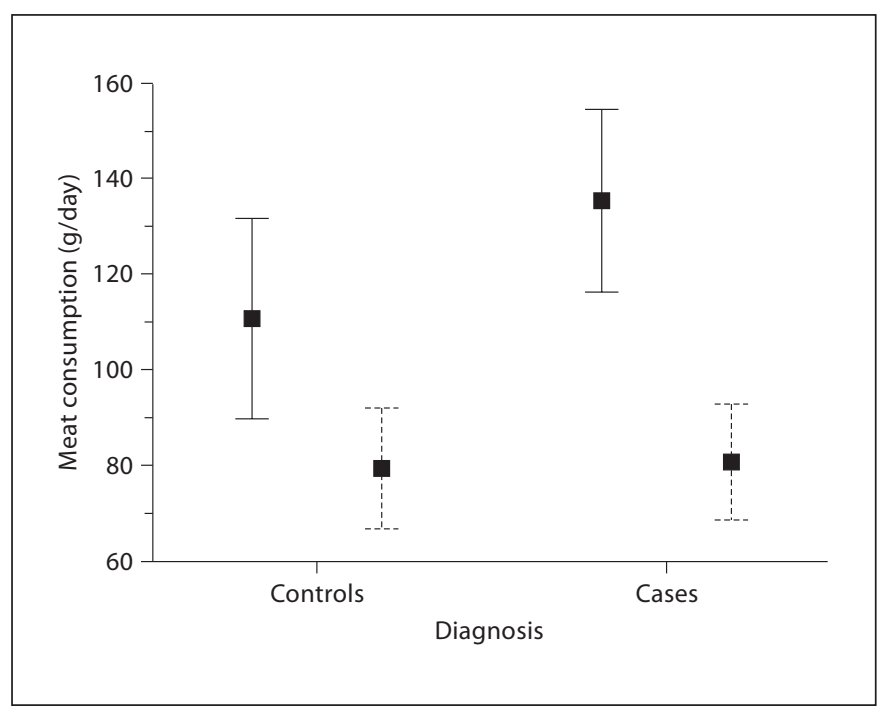

Fig. 1. Total current meat consumption in ET cases versus controls. Men = Solid bars; women = dashed bars. Each bar represents $\pm 2 \mathrm{SE}$, and each box represents the mean. body mass index and current smoking), higher total current meat consumption in males was associated with ET $(\mathrm{OR}=1.007,95 \% \mathrm{CI}=1.001-1.014, \mathrm{p}=0.02)$.

ET cases and controls were stratified into quartiles of total current meat consumption (tables 2,3 ). In an unadjusted logistic regression analysis in males, the cases had a nine times higher odds of being in the highest versus lowest (reference) quartile than controls (unadjusted $\mathrm{OR}=9.29,95 \% \mathrm{CI}=2.29-37.64, \mathrm{p}=0.002$ ), and in adjusted analyses, the odds were higher $(\mathrm{OR}=21.36,95 \%$ $\mathrm{CI}=3.52-129.51, \mathrm{p}=0.001$ after adjusting for age, education, body mass index and current smoking). In cases, total current meat consumption was not correlated with total tremor score (Spearman's rho $=-0.15, \mathrm{p}=0.10$ ).

Past (5 years ago) total meat consumption was assessed in 15 males with ET of less than 5 years' duration (i.e., predisease diet) and 60 male controls: $146.5 \pm 68.6$ versus $131.4 \pm 99.1 \mathrm{~g} /$ day (Mann-Whitney $\mathrm{z}=1.11, \mathrm{p}=0.27$ ). In a logistic regression analysis in males, cases had higher odds of being in the highest versus lowest (reference) quartile of past total meat consumption than controls (unadjusted $\mathrm{OR}=6.33,95 \% \mathrm{CI}=0.67-60.16, \mathrm{p}=0.11$ and $\mathrm{OR}=10.00,95 \% \mathrm{CI}=0.84-119.09, \mathrm{p}=0.069$ after adjusting for age, education, body mass index and current smoking).

Additional dietary data were available on a subset of 31 male ET cases and 26 male controls. There were no case-control differences in consumption of other food groups. Male cases and controls consumed similar quantities of carbohydrate $(172.6 \pm 64.6$ vs. $161.6 \pm 72.3 \mathrm{~g} /$ day, $\mathrm{t}=0.61, \mathrm{p}=0.55)$ and vegetable fat $(20.8 \pm 8.5 \mathrm{vs}$. $19.9 \pm 12.3 \mathrm{~g} / \mathrm{day}, \mathrm{t}=0.32, \mathrm{p}=0.75)$, indicating that the case-control difference in animal protein (i.e., meat) consumption did not extend to other major food groups.

One explanation for the increased meat consumption we observed might be that ET cases adjust their diets to 
include foods that are easy to eat despite tremor. Meat can be a very solid, stable food and can be more easily managed. On the other hand, some meats require a great deal of dexterity during processing (e.g., holding the meat in place with a fork in one hand and using the other hand to cut it with a knife), so that ET cases might preferentially avoid eating these meats. We examined 15 different meat types. The two for which there was the greatest male case-control difference were grilled, barbecued or broiled chicken $(18.6 \pm 26.9$ vs. $9.0 \pm 13.7 \mathrm{~g} / \mathrm{day}, \mathrm{t}=2.40, \mathrm{p}=$ 0.02 ) and meat or sausage patties other than hamburgers $(2.3 \pm 5.2$ vs. $0.8 \pm 1.9 \mathrm{~g} /$ day, $\mathrm{t}=2.05, \mathrm{p}=0.04$; while chicken can be eaten either with or without utensils, meat patties generally require utensils), whereas for solid, stable, hand-held meats (e.g., hamburgers), the consumption was similar in cases and controls $(13.8 \pm 19.2$ vs. $12.7 \pm$ $21.6 \mathrm{~g} / \mathrm{day}, \mathrm{t}=0.31, \mathrm{p}=0.76$ ). These data argue against the notion that our results are solely due to an increased consumption of meats as solid, stable food in persons with tremor.

Total current meat doneness level was similar in male ET cases and male controls $(9.7 \pm 2.9$ vs. $10.0 \pm 3.8$, Mann-Whitney $\mathrm{z}=0.73, \mathrm{p}=0.47$ ) and in female cases and female controls $(8.5 \pm 3.2$ vs. $9.3 \pm 3.7$, Mann-Whitney $\mathrm{z}=1.40, \mathrm{p}=0.16$ ). Analyses that adjusted for age, education, body mass index and current smoking did not reveal any case-control differences.

\section{Discussion}

Dietary factors have been examined as possible disease contributors in Parkinson's disease and many other neurological disorders. The dietary epidemiology of ET, however, has not been rigorously studied; there have been few studies $[18,19]$, and, therefore, little is known about the association between ET and dietary factors. Harmane and other heterocyclic amines are found in high concentrations in cooked muscle foods (i.e., meats). A limitation of standardized food frequency questionnaires is that they do not include questions on meat cooking practices, and they have few specific questions on meat consumption. We used a detailed meat questionnaire $[14,15]$ to test the hypothesis that meat consumption and level of meat doneness would be higher in ET cases than controls. Current meat consumption was greater in male ET cases than controls, with these cases having a nine times higher odds of being in the highest versus lowest current meat consumption quartile than controls. Meat cooking practices did not differ. In a subsample of cases with disease of short duration, predisease diet was assessed, and the results were similar: male cases had higher odds of being in the highest versus lowest (reference) quartile than controls, although these analyses were of limited power. There was no apparent case-control difference in meat cooking practices (i.e., level of meat doneness); this suggests that it is the quantity of meat consumed rather than the way in which that meat is prepared that is likely to contribute to any increased dietary harmane intake in ET.

This study suggests, at least in males, that there are dietary differences between ET cases and controls. Whether these dietary differences are contributing to higher blood harmane concentrations in ET cases would need to be addressed by assessing correlations between meat intake and blood harmane concentrations. Furthermore, these data do not directly address whether ET cases or family members who are at risk of ET should eat less meat; an interventional study is needed to address this issue.

The difference we observed was restricted to men and was not observed in women. Other evidence of gender differences in ET exist [20-22]. A far larger proportion of women than men with ET have head tremor [20], and childhood onset ET is largely a phenomenon of boys rather than girls [21, 22]. Other studies have demonstrated a higher prevalence of ET in men than women [23]. These data suggest that disease expression and, possibly, disease mechanisms could differ in males and females. In other neurological disorders (e.g., Parkinson's disease), dietary risk factors have been shown to differ substantially by gender [24].

We also collected additional dietary data on a subset of ET cases and controls, demonstrating that the casecontrol difference in animal protein (i.e., meat) consumption did not extend to other major food groups. Similarly, in previous analyses, we did not detect a case-control difference in nutritional antioxidant intake in ET cases and controls [19].

A limitation of this study was the use of current (i.e., within the past year) dietary data rather than past consumption. If we had assessed predisease consumption, we would have been able to address whether dietary consumption patterns differed between cases and controls prior to disease onset in cases. However, the mean disease duration in our cases was close to two decades, and the validity of long-term recall of past diet is questionable. Studies have shown fairly low correlations $(\mathrm{r}=0.13-0.42)$ between estimates of food intake originally assessed by interview and then recalled $15-25$ years later $[25,26]$. One 
way to deal with this limitation would be to assess baseline diet in a disease-free cohort, and then follow participants until the onset of disease (i.e., a prospective cohort rather than a case-control study). Ours was a casecontrol rather than a cohort study. Working with this limitation, we presented retrospective data on predisease diet in a sample of cases with recent-onset disease. In these analyses, results were similar to those of our main analyses.

The strengths of this study are that there are few available data on the dietary epidemiology of ET. Furthermore, this is the only study to begin to examine this specific dietary question in relation to ET. Finally, we used a large sample of cases and comparable controls from the same source population.
In summary, dietary factors have been examined as possible disease contributors in Parkinson's disease and other neurological disorders. In the current analyses, we provide preliminary evidence for a dietary difference between ET cases and controls. Whether this dietary difference is of etiological significance deserves further investigation.

\section{Acknowledgments}

Supported by grants R01 NS039422, R01 NS042859, P30 ES009089 and RR00645 (General Clinical Research Center, NIH, Bethesda, Md., USA).

\section{References}

1 Benito-Leon J, Bermejo-Pareja F, Morales JM, Vega S, Molina JA: Prevalence of essential tremor in three elderly populations of central Spain. Mov Disord 2003;18:389394.

-2 Dogu O, Sevim S, Camdeviren H, Sasmaz T, Bugdayci R, Aral M, Kaleagasi H, Un S, Louis ED: Prevalence of essential tremor: door-to-door neurological exams in Mersin Province, Turkey. Neurology 2003;61:18041806.

-3 Benito-Leon J, Bermejo-Pareja F, Louis ED: Incidence of essential tremor in three elderly populations of central Spain. Neurology 2005;64:1721-1725.

-4 Higgins JJ, Loveless JM, Jankovic J, Patel PI: Evidence that a gene for essential tremor maps to chromosome $2 p$ in four families. Mov Disord 1998;13:972-977.

5 Louis ED: Etiology of essential tremor: should we be searching for environmental causes? Mov Disord 2001;16:822-829.

6 De Meester C: Genotoxic potential of betacarbolines: a review. Mutat Res 1995;339: 139-153.

7 Anderson NJ, Tyacke RJ, Husbands SM, Nutt DJ, Hudson AL, Robinson ESJ: In vitro and ex vivo distribution of $\left[{ }^{3} \mathrm{H}\right]$ harmane, an endogenous $\beta$-carboline, in rat brain. Neuropharmacology 2006;50:269-276.

-8 Martin FC, Thu Le A, Handforth A: Harmaline-induced tremor as a potential preclinical screening method for essential tremor medications. Mov Disord 2005;20:298-305.

$\checkmark 9$ Handforth A, Krahl SE: Suppression of harmaline-induced tremor in rats by vagus nerve stimulation. Mov Disord 2001;16:8488.
10 O’Hearn E, Molliver ME: Degeneration of Purkinje cells in parasagittal zones of the cerebellar vermis after treatment with ibogaine or harmaline. Neuroscience 1993;55: 303-310.

11 Louis ED, Zheng W, Jurewicz EC, Watner D, Chen J, Factor-Litvak P, Parides M: Elevation of blood $\beta$-carboline alkaloids in essential tremor. Neurology 2002;59:1940-1944.

12 Louis ED, Zheng W, Applegate L, Shi L, Factor-Litvak P: Blood harmane concentrations and dietary protein consumption in essential tremor. Neurology 2005;65:391-396.

13 Louis ED, Applegate L, Graziano J, Parides M, Slavkovich V, Bhat $\mathrm{H}$ : Interaction between blood lead concentration and deltaamino-levulinic acid dehydratase gene polymorphisms increases the odds of essential tremor. Mov Disord 2005;20:1170-1177.

14 Keating GA, Bogen KT, Chan JM: Development of a meat frequency questionnaire for use in diet and cancer studies. J Am Diet Assoc 2007;107:1356-1362.

15 Bogen KT, Keating GA 2nd, Chan JM, Paine LJ, Simms EL, Nelson DO, Holly EA: Highly elevated PSA and dietary PhIP intake in a prospective clinic-based study among African Americans. Prostate Cancer Prostatic Dis 2007;10:261-269.

-16 Willett WC, Sampson L, Stampfer MJ, Rosner B, Bain C, Witschi J, Hennekens $\mathrm{CH}$, Speizer FE: Reproducibility and validity of a semiquantitative food frequency questionnaire. Am J Epidemiol 1985;122:51-65.

17 Louis ED, Ford B, Lee H, Andrews H: Does a screening questionnaire for essential tremor agree with the physician's examination? Neurology 1998;50:1351-1357.
18 Prakash KM, Fook-Choong S, Yuen Y, Tan EK: Exploring the relationship between caffeine intake and essential tremor. J Neurol Sci 2006;251:98-101.

19 Louis ED, Jurewicz EC, Parides M: Casecontrol study of nutritional antioxidant intake in essential tremor. Neuroepidemiology 2005;24:203-208.

20 Louis ED, Ford B, Frucht S: Factors associated with increased risk of head tremor in essential tremor: a community-based study in northern Manhattan. Mov Disord 2003; 18:432-436.

21 Louis ED, Dure L, Pullman S: Essential tremor in childhood. Mov Disord 2001;16: 921-923.

22 Tan EK, Lum SY, Prakash KM: Clinical features of childhood onset essential tremor. Eur J Neurol 2006;13:1302-1305.

23 Mancini ML, Stracci F, Tambasco N, Sarchielli P, Rossi A, Calabresi P: Prevalence of essential tremor in the territory of Lake Trasimeno, Italy: results of a population-based study. Mov Disord 2007;22:540-545.

24 Chen H, O'Reilly E, McCullough ML, Rodriguez C, Schwarzschild MA, Calle EE, Thun MJ, Ascherio A: Consumption of dairy products and risk of Parkinson's disease. Am J Epidemiol 2007;165:998-1006.

25 Byers TE, Rosenthal RI, Marshall JR, Rzepka TF, Cummings KM, Graham S: Dietary history from the distant past: a methodologic study. Nutr Cancer 1983;5:69-77.

26 Thompson FE, Lamphiear DE, Metzner HL, Hawthorne VM, Oh MS: Reproducibility of reports of frequency of food use in the Tecumseh Diet Methodology Study. Am J Epidemiol 1987;125:658-671. 